\title{
Study of the Heat Transfer Effect in Moxibustion Practice
}

\author{
Chinlong Huang and Tony W. H. Sheu \\ Dept of Engineering Sciences and Ocean Engineering, \\ National Taiwan University, No. 1, Sec. 4, Roosevelt Road, Taipei, 10617
}

Taiwan

\section{Introduction}

"First you use the needle (acupuncture), then the fire (moxibustion), and finally the herbs" (Tsuei, 1996) has been well known in traditional Chinese medicine (TCM). In fact, moxibustion has played an important role in Asia for many years (Zhang, 1993). In Huang Di Nei Jing (Maoshing (translator), 1995), we can find that when needle can't do a job, moxa is a better choice. Moxibustion rather than acupuncture was commonly known to be able to alleviate pains due to some severe diseases, manifested by vacuity cold and Yang deficiency. In clinical studies, many experiments have confirmed that moxibustion is capable of enhancing immunity, improving circulation, accommodating nerve, elevating internal secretion and adjusting respiration, digestion and procreation et al. (Wu et al., 2001; Liu, 1999). However, moxibustion has not been accepted as the modern therapy because of the lack of standard practice procedures. In addition, moxibustion is subject to the danger of scalding patients. More effort needs therefore to be made so as to increase our knowledge about the moxibustion and, hopefully, these research endeavors can be useful for the future instrumentation and standardization of the moxibustion by some emerging modern scientific techniques.

The existing moxibustion techniques can be separated into the direct and indirect moxibustion therapies. In direct moxibustion, the ignited cone-shaped moxa is normally placed on the skin surface near acupoints (Fig. 1(a)). Direct moxibustion can be further categorized into the scarring and non-scarring two types. During the scarring moxibustion, the ignited moxa is placed on the top of an acupoint till a time it burns out completely. This moxibustion type may lead to a localized scarring or blister. In non-scarring moxibustion, moxa cone is also burned directly on the skin. Such an ignited moxa will be removed when it may cause an intense pain (moxa temperature should be under $60^{\circ} \mathrm{C}$ ). Usually, this treatment will result in a small red circular mark on the local area of the skin surface.

Indirect moxibustion becomes more popular currently because of its lower risk of leading to pain or burning. A common way of administering the therapeutic properties of moxibustion is to place, for example, a piece of ginger, garlic, salt or pepper in between the burning moxa and the skin. One can also ignite a moxa stick, which is placed at a location that is closed to but not in contact with the proper acupoint (about $2 \mathrm{~cm}$ to skin surface normally), for several minutes until the color of the skin surface near this acupoint turns red. 


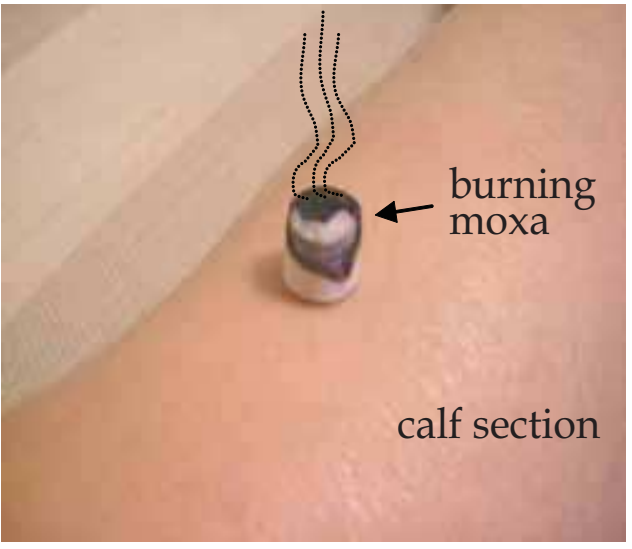

(a)

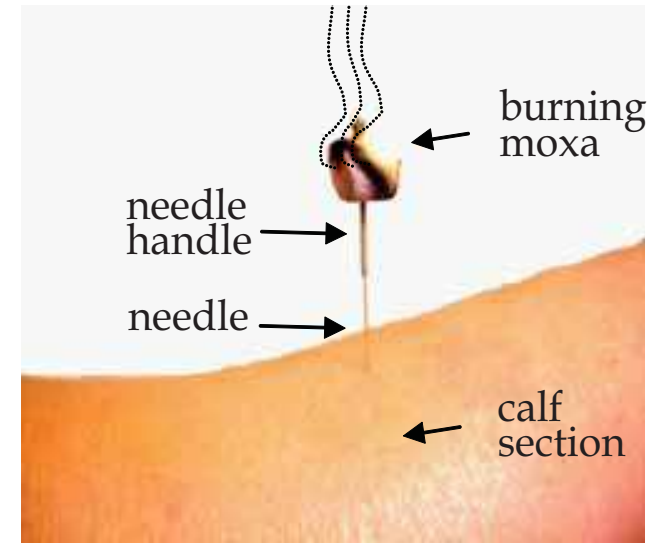

(b)

Fig. 1. Schematic of the moxibustions. (a) Direct moxibustion therapy; (b) Warm needle moxibustion therapy

Another indirect moxibustion involves the use of needles and moxa. One needle, along which there is a moxa, is inserted into the skin near an acupoint. The moxa cone placed on the inserted needle is then ignited. The heat generated from the burning moxa will propagate through the needle and transfers to the acupoint by heat conduction. During the treatment, a dried moxa is in contact with the handle of the acupuncture needle after the needle being inserted into the acupuncture point. This is followed by igniting the moxa and keeps it burning (Fig. 1(b)). Typically, the distance between the skin surface and the burning moxa stick is about $2 \mathrm{~cm}$. Heat will be conducted from the needle handle to the needle itself and, finally, to the surrounding tissues. This acupuncture design with a burning moxa can result in a certain temperature gradient across the needle and enhances thus the Seebeck effect (Cohen, 1997). In Chinese medicine theory, this method is highly recommended for use to the patients with vacuity cold and wind damp (Wiseman, 1998) because of its functions of warming the meridians and promoting the qi- and blood-flow. This therapy is also applicable to release the cold-damp syndrome for the patients with rheumatoid arthritis ( $\mathrm{Li}, 1999)$. The other technique is called as the fire needle, which involves holding the needle in a lamp flame until it becomes very hot. Afterwards, the needle is inserted to the appropriate depth in the body quickly and it will be removed later on (Unschuld, 1988). In comparison with the fire needle, the warming needle permits a longer retention and a gentler heating.

In the present study, our aim is to study two types of the moxibustion effect, which are the direct moxibustion and the warm needle moxibustion therapy. The acupoint GB 38 shown in Fig. 2 is one of the acupoints in gall bladder (GB) meridian, which has an association with the hemicrania and joint ache. Figure 3 shows the axial image of the right leg for the GB38 acupoint (Courtesy of Yang (1997)). At the calf section, the number of capillaries near the GB acupoints is greater than those at the other parts of the body (Fei, 2000). Also, the distances between the three acupoints GB37-GB38 and GB38-GB39 have about an inch. Therefore, the acupoint GB38 was also the focus of other investigations (Sheu and Huang, 2008; Huang and Sheu, 2008; Huang and Sheu, 2009). 


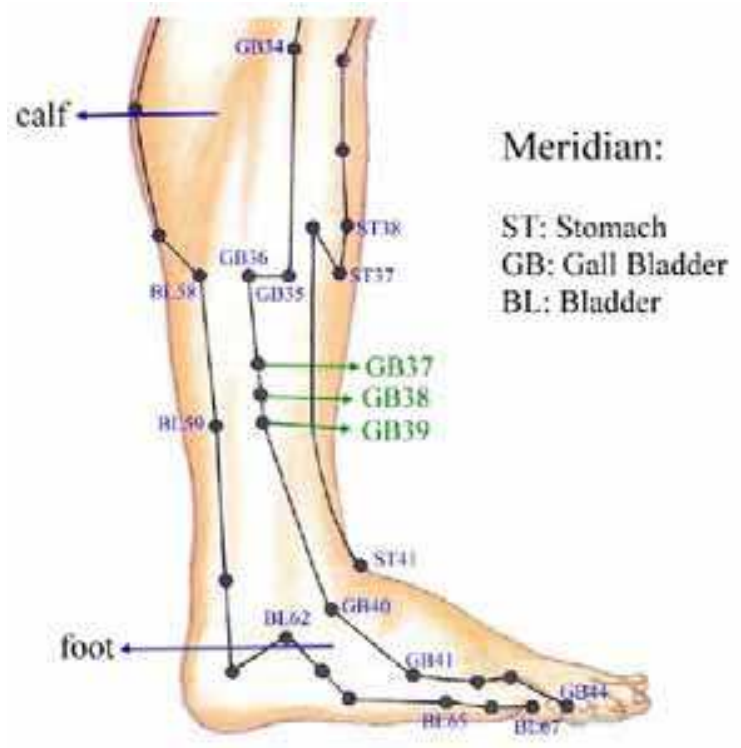

Fig. 2. Schematic of the stomach, gall bladder and bladder meridians. Note that GB38 is the acupoint under current investigation (Chang, 1999)

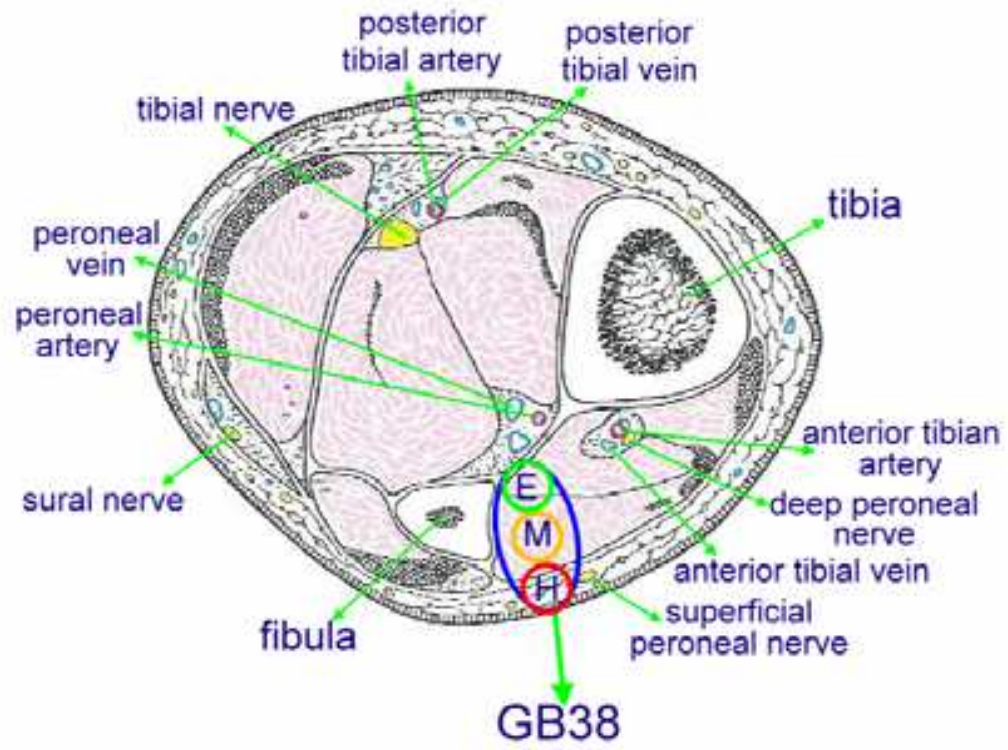

$\mathrm{H}$ : heaven; $\mathrm{M}$ : man; $\mathrm{E}$ : earth

Fig. 3. One axial image of the right leg that contains the GB38 acupoint (Courtesy of Yang 1997). Heaven, man and earth are three depths beneath of the skin surface 


\section{Materials and methods}

Heat transfer process will be modelled by solving the energy conservation equation. In this study, the energy equation cast in the following form for the total enthalpy will be employed

$$
\frac{\partial\left(\rho h_{0}\right)}{\partial t}=\nabla \cdot(k \nabla T)
$$

In the above equation, $h_{0}, k, \rho$ and $T$ denote the internal energy, thermal conductivity, density, and temperature, respectively.

Simulation of equation (1) will be carried out by employing the commercially available finite volume package, namely, CFDRC (CFD-ACE-GUI, 2003). This software package provides the modules CFD-GEOM for grid generation, $\mathrm{CFD}^{-\mathrm{ACE}^{+}}$for solution solver, and CFDVIEW for post-processing. A convenient graphical user interface (GUI) is also available for us to specify the physical properties of the medium under investigation, and the specification of the boundary and initial conditions. In CFD-ACE+ solver, the finite volume method employed together with the algebraic multigrid method and the conjugate gradient squared solution solver accelerates calculation. In this study, the central difference scheme is chosen to approximate the parabolic type partial differential equation.

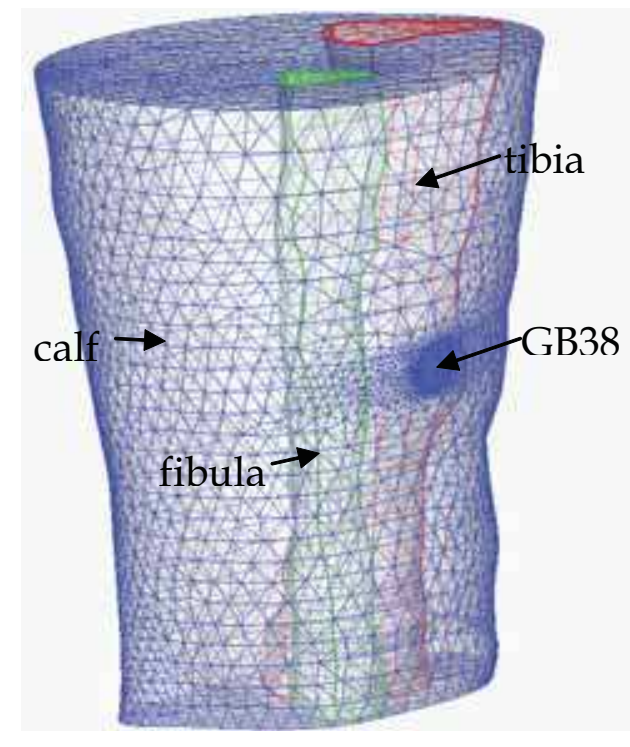

(a)

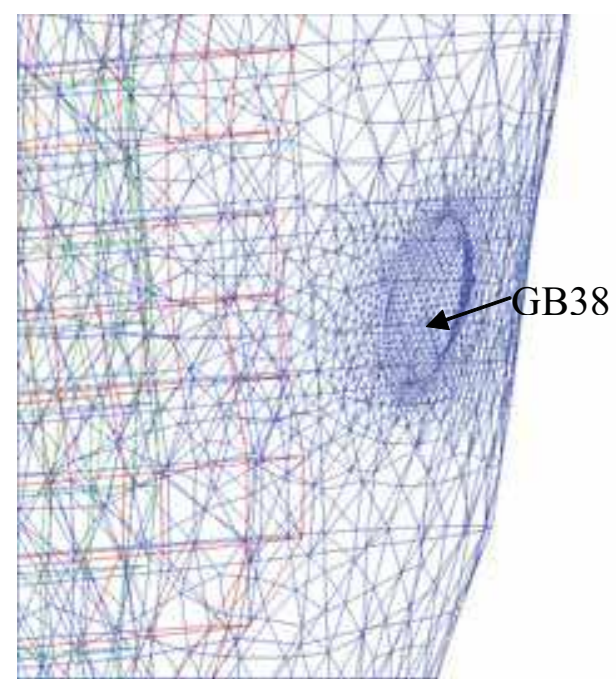

(b)

Fig. 4. (a) The generated surface meshes for the investigated calf section; (b) The zoom-in area around GB38

A hybrid mesh, containing the structured- and unstructured-type meshes, shown in Fig. 4, is generated from a total number of 17,000 nodal points. These mesh points have been properly distributed so that the predicted solutions can more accurately represent the 
physical phenomenon. In all the investigations, calculation of the enthalpy will be terminated when the residual norms fall below $10^{-15}$. As the number of the employed nodal points (with 17,000 nodal points) is increased by $50 \%$ (25,500 nodal points), only a negligibly small difference is seen in the simulated results. On the contrary, when the number of the mesh points is decreased by $50 \%$ (or 8,500 nodal points) the computed difference shows an apparent difference. Hence the mesh generated by 17,000 nodal points will be employed in the present simulation.

In order to know the temperature distribution due to the ignited moxa, the IR images are collected under the almost dark condition. Both of the camera and the subject are kept apart from the external draft IR source. The room temperature and the relative humidity are kept at $22 \pm 0.1^{\circ} \mathrm{C}$ and $60 \pm 7 \%$, respectively. Thermography is taken using a calibrated $\mathrm{IR}$ camera (ThermaCAM® SC500 from FLIR Systems TM) (ThermaCAM SC500 Operator's Manual), which is equipped with a $45^{\circ}$ close-up optic. Sensitivity, accuracy and resolution of the employed camera are kept at $0.07{ }^{\circ} \mathrm{C}, \pm 2{ }^{\circ} \mathrm{C}$ and $320 \times 240$ pixels, respectively. The distance between the camera and the subject under current investigation is $0.1 \mathrm{~m}$. The infrared images of the subject obtained at a sampling rate of $4 \mathrm{~Hz}$ will be directly recorded in the computer's hard disk.

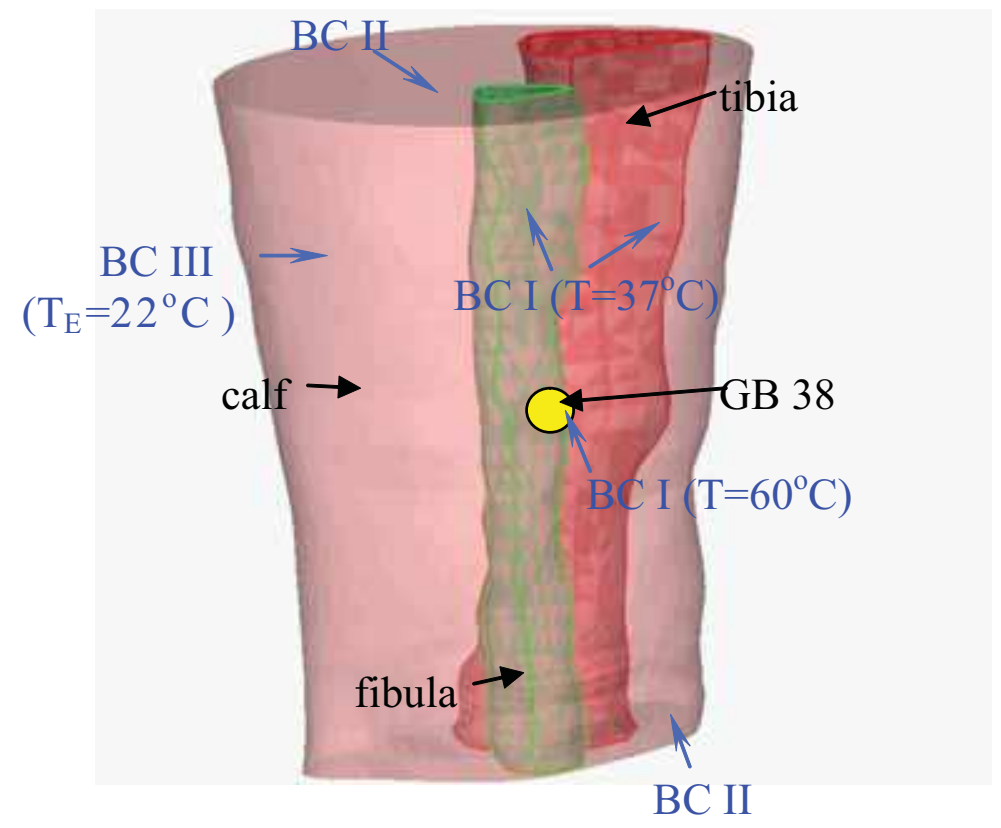

BC I: isothermal $\quad$ BC II: symmetry BC III: external heat transfer (by convection)

Fig. 5. Schematic of the calf section around the acupoint GB 38 and the specified boundary conditions 


\section{Results and discussion}

In the present study, direct moxibustion and warm needle moxibustion treatments are described below:

\section{(A) Direct moxibustion therapy}

In direct moxibustion therapy, a burned moxa (moxa cone of $1 \mathrm{~cm}$ diameter and $1 \mathrm{~cm}$ length, made by the dried Artemisia vulgaris leaves with a weight of $100 \mathrm{mg}$ ), was placed on acupoint GB38 shown in Fig. 4. The boundary conditions applied at the calf section with tibia and fibula are shown in Fig. 5, where BC I, II and III represent the isothermal, symmetric and heat transfer (by convection) boundary conditions, respectively. In $\mathrm{BC}$ III, the wall subtype is chosen to account for the transfer of heat to/ from the external environment (i.e., the area outside of the computational system) by heat convection. On the boundary $\mathrm{BC} \mathrm{II}$, it is specified by the condition

$$
q_{w}=h_{c}\left(T_{E}-T_{w}\right)
$$

where $h_{c}$ and $T_{E}$ denote the heat transfer coefficient and the environment temperature. The wall temperature $\left(T_{w}\right)$ is determined by balancing the heat fluxes between the environment and the skin surface.

The heat transfer coefficient of the skin surface, specific heat and the density of tissues in the investigated calf section are denoted as $h_{\mathrm{c}}, C p_{\mathrm{c}}$ and $\rho_{\mathrm{c}}$, respectively. At the normal state, these coefficients are prescribed respectively with $h_{\mathrm{c}}=3.7 \mathrm{~W} / \mathrm{m}^{2{ }^{\circ}} \mathrm{C}$ (Nishi and Gagge, 1970), $C p_{\mathrm{c}}=3,594 \mathrm{~J} \mathrm{~kg}^{\mathrm{o}} \mathrm{C}$ (Blake et al., 2000) and $\rho_{\mathrm{c}}=1,035 \mathrm{~kg} / \mathrm{m}^{3}$. The thermal conductivity of the human tissues is assumed to change with the temperature $(T)$ by the equation $k_{\mathrm{c}}=0.840419+$ $0.001403 T \mathrm{~W} / \mathrm{m}^{\circ} \mathrm{C}$ (Mura et al., 2006). The rest of the employed coefficients are tabulated in the Table 1.

\begin{tabular}{|l|l|l|}
\hline $\mathrm{k}_{\mathrm{s}}$ & $16 \mathrm{~W} / \mathrm{m}^{\circ} \mathrm{C}$ & Thermal conductivity of the stainless steel \\
\hline $\mathrm{k}_{\mathrm{c}}$ & $0.840419+0.001403 \mathrm{~T} \mathrm{~W} / \mathrm{m}^{\circ} \mathrm{C}$ & Thermal conductivity of the calf \\
\hline $\mathrm{k}_{\mathrm{a}}$ & $0.0299 \mathrm{~W} / \mathrm{m}^{\circ} \mathrm{C}$ & Thermal conductivity of the air \\
\hline $\mathrm{Cp}_{\mathrm{s}}$ & $460 \mathrm{~J} \mathrm{~kg}{ }^{\circ} \mathrm{C}$ & Specific heat of the stainless steel \\
\hline $\mathrm{Cp}_{\mathrm{c}}$ & $3,594 \mathrm{~J} \mathrm{~kg}{ }^{\circ} \mathrm{C}$ & Specific heat of the calf \\
\hline $\mathrm{Cp}_{\mathrm{a}}$ & $1,009 \mathrm{~J} \mathrm{~kg}{ }^{\circ} \mathrm{C}$ & Specific heat of the air \\
\hline$\rho_{\mathrm{s}}$ & $7,800 \mathrm{~kg} / \mathrm{m}^{3}$ & Density of the stainless steel \\
\hline$\rho_{\mathrm{c}}$ & $1,035 \mathrm{~kg} / \mathrm{m}^{3}$ & Density of the calf \\
\hline$\rho_{\mathrm{a}}$ & $1.0 \mathrm{~kg} / \mathrm{m}^{3}$ & Density of the air \\
\hline $\mathrm{h}_{\mathrm{s}}$ & $7.9 \mathrm{~W} / \mathrm{m}^{2}{ }^{\circ} \mathrm{C}$ & Heat transfer coefficient of the stainless steel \\
\hline $\mathrm{h}_{\mathrm{c}}$ & $3.7 \mathrm{~W} / \mathrm{m}^{2}{ }^{\circ} \mathrm{C}$ & Heat transfer coefficient of the calf \\
\hline $\mathrm{T}_{\mathrm{E}}$ & $22^{\circ} \mathrm{C}$ & Environment temperature \\
\hline
\end{tabular}

Table 1. Summary of the coefficients and the prescribed temperatures in the current simulation

The predicted temperature on the skin surface is plotted in Fig. 6. The moxa temperature on the skin surface is specified at $60{ }^{\circ} \mathrm{C}$ (non-scarring direct moxibustion), which is the highest 
temperature that our skin can possibly endure, to avoid scarring. On the tibia and fibula, their temperatures are given to be $T=37^{\circ} \mathrm{C}$, which is the same as the normal human body temperature. One can find from the upper and bottom planes of the simulated domain that the temperature near tibia and fibula has a larger value (Fig. 6). Since moxibustion takes place at a location near GB38, the area around this acupoint has a higher temperature. Figure 7 shows the predicted skin surface temperature that is distributed in a form similar to the experimentally measured temperature by IR image.

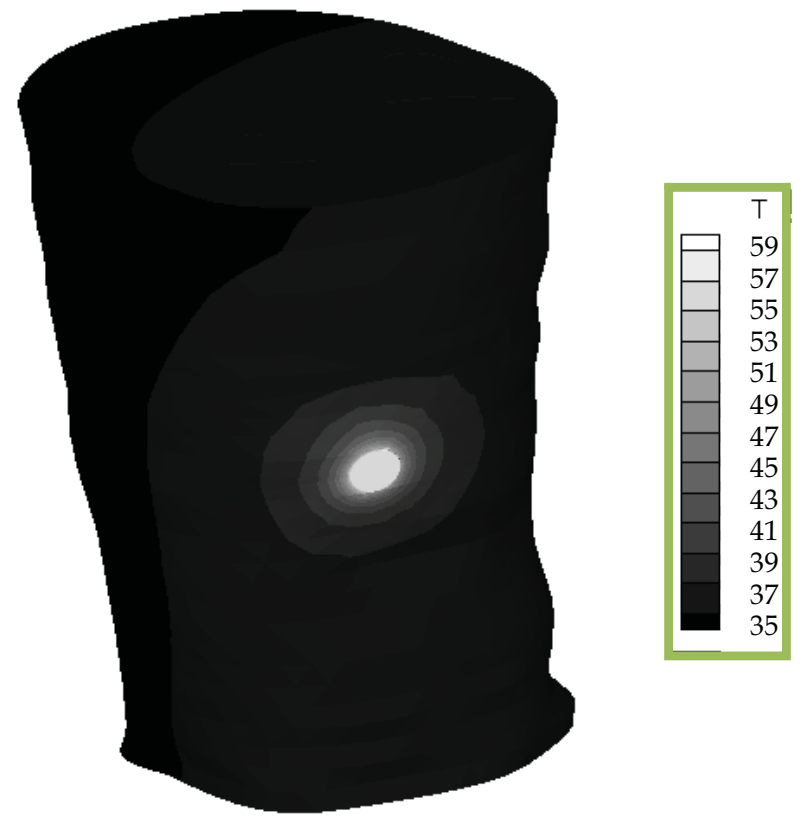

Fig. 6. The predicted skin surface temperature contours subject to the moxibustion

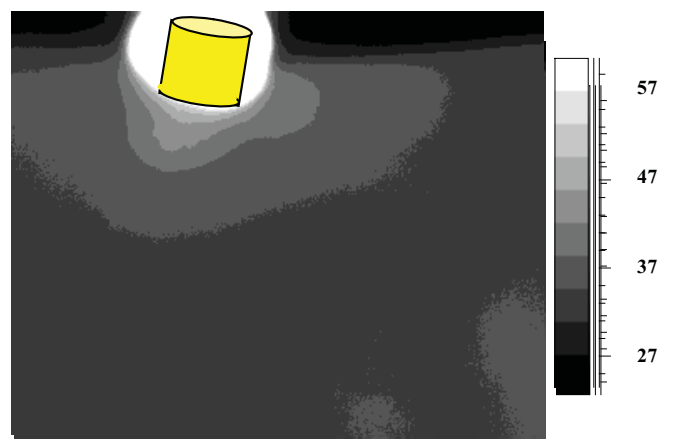

(a)

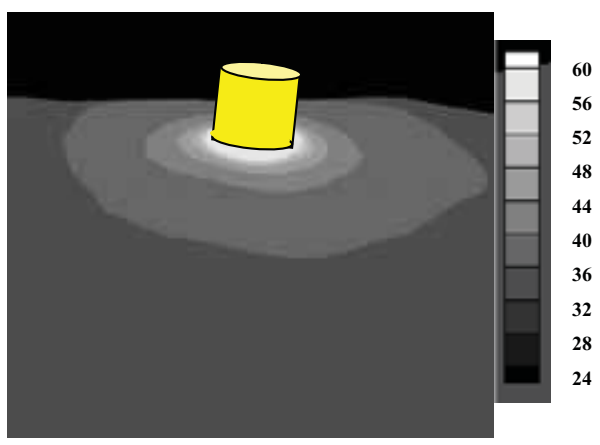

(b)

Fig. 7. Comparison of the predicted and measured temperatures. (a) Measured by the IR image recording system; (b) Predicted by the numerical simulation 


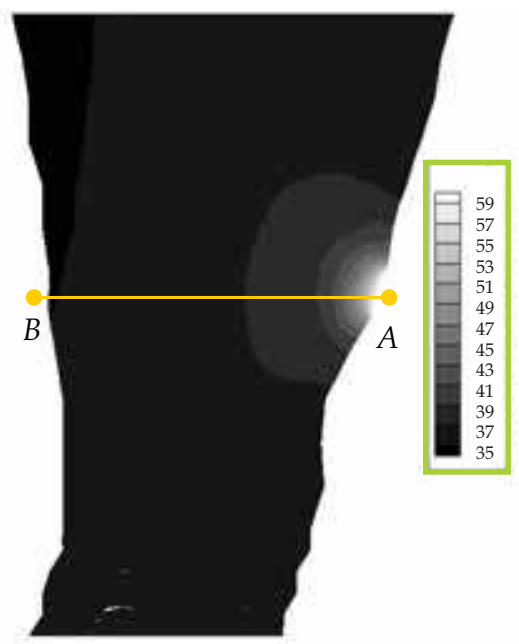

(a)

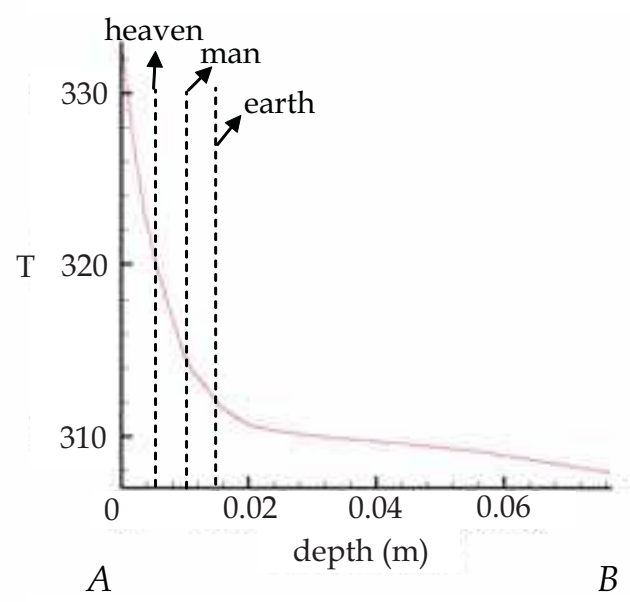

(b)

Fig. 8. (a) The predicted temperature contours on the cutting plane that passes through the acupoint GB38 when the moxa temperature on the skin surface is $60^{\circ} \mathrm{C}$; (b) The predicted temperature profile along the line connected by two points $A$ and $B$ shown in Fig. 8(a). The "heaven", "man" and "earth" represent three depths of the investigated acupoints, respectively

In TCM, there is one concept, "When using acupuncture, shallow position treats diseases nearby; deep position treats diseases far away". Huang Di Nei Jing (Maoshing (translator), 1995) supported the similar concept that at the same acupoint shallow position treats mild diseases; deep position treats severe diseases. This enlightens that at the same acupoint different depths have different effects and even have an association with different diseases. For this reason, this study makes an effort to get the temperature distributions at different depths. Figure 8 (a) shows the temperature contours predicted at the plane of the acupoint GB38 for the case that the moxa temperature on the skin surface is $60^{\circ} \mathrm{C}$. From Fig. 8 (b), one can see the predicted temperature profile along a line that is connected by two nodes $A$ and $B$. For the acupoints "heaven", "man" and "earth", they have three different depths at a location in between the skin surface and the associated connective tissue. When the moxa temperature is controlled at $60^{\circ} \mathrm{C}$, which is the temperature considered in the case of nonscarring moxibustion, the temperatures at the "heaven" ( $\sim 0.5 \mathrm{~cm}$ beneath of the skin surface), "man" ( $1.0 \mathrm{~cm}$ beneath of the skin surface) and "earth" $(\sim 1.5 \mathrm{~cm}$ beneath of the skin surface) are predicted as $T_{\text {heaven }}^{60}=47.8^{\circ} \mathrm{C}, T_{\text {man }}^{60}=41.7^{\circ} \mathrm{C}$ and $T_{\text {earth }}^{60}=39.0^{\circ} \mathrm{C}$. From the skin surface to "heaven", we found that temperature decreases faster ( $12.2^{\circ} \mathrm{C}$ in between) than those from the "heaven" to "man" $\left(6.1^{\circ} \mathrm{C}\right.$ in between) and from the "man" to "earth" ( $2.7^{\circ} \mathrm{C}$ in between) as well because our body has a bigger thermal capacity than that of the moxa. As a result, the temperature variation on the side of "heaven" is greater than that along the "earth". The relation between the predicted temperature $(T)$ and the depth $(x)$ can be expressed as

$$
T=60-5.31 \times 10^{-2} x+5 \times 10^{-5} x^{2}-3 \times 10^{-8} x^{3}+7 \times 10^{-12} x^{4}-1 \times 10^{-15} x^{5}+6 \times 10^{-20} x^{6}
$$




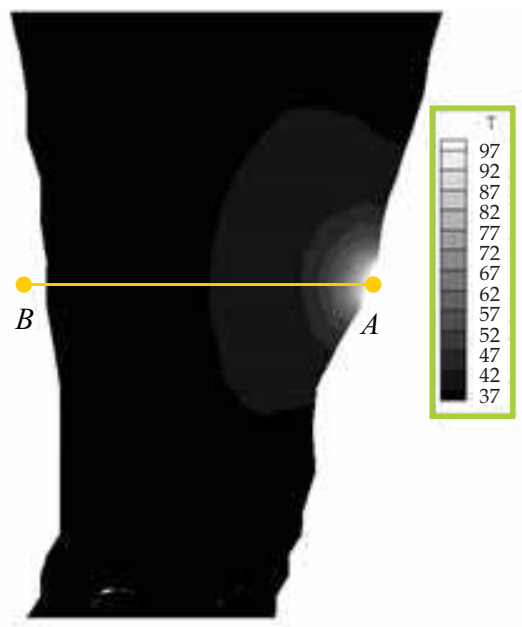

(a)

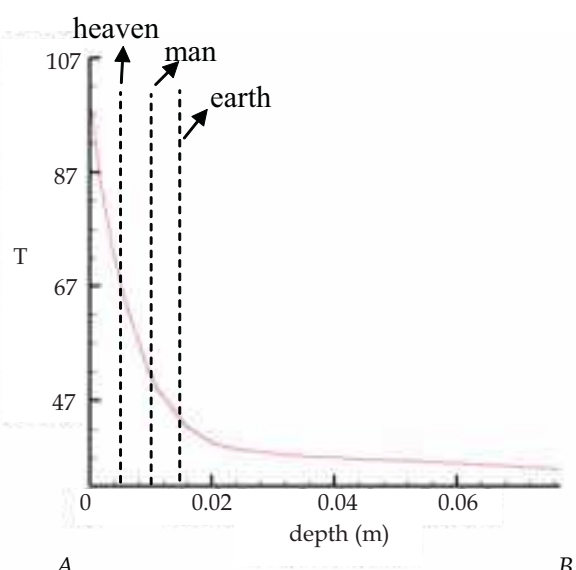

(b)

Fig. 9. (a) The predicted temperature contours on the cutting plane that passes through the acupoint GB38 when the moxa temperature on the skin surface is $100^{\circ} \mathrm{C}$; (b) The predicted temperature profile along the line connected by two points $A$ and $B$ shown in Fig. 9(a). The "heaven", "man" and "earth" represent three depths of the investigated acupoints, respectively

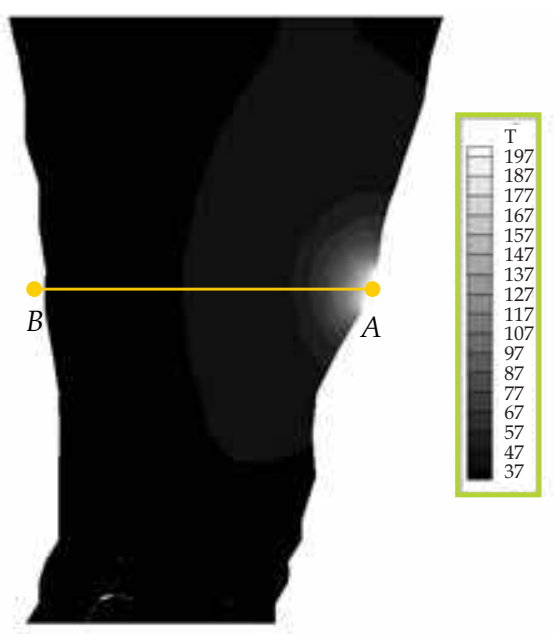

(a)

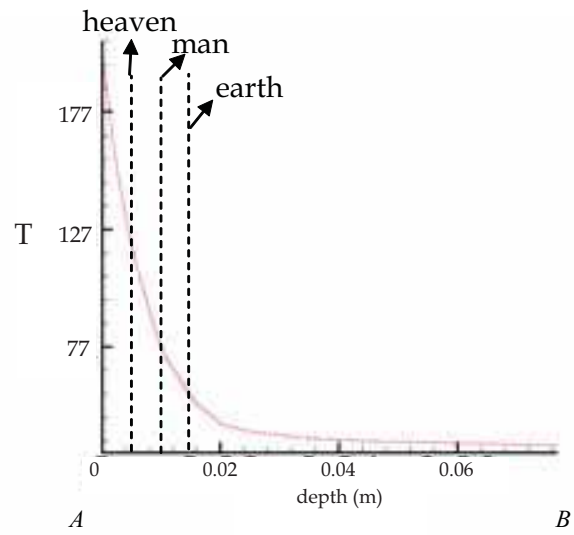

(b)

Fig. 10. (a) The predicted temperature contours on the cutting plane that passes through the acupoint GB38 when the moxa temperature on the skin surface is $200^{\circ} \mathrm{C}$; (b) The predicted temperature profile along the line connected by two points $A$ and $B$ shown in Fig. 10(a). The "heaven", "man" and "earth" represent three depths of the investigated acupoints, respectively 
We then consider the scarring moxibustion by specifying the moxa temperatures at two higher temperatures 100 and $200{ }^{\circ} \mathrm{C}$. The temperatures at three locations are predicted to be $T_{\text {heaven }}^{100}=68.1^{\circ} \mathrm{C}, T_{\text {man }}^{100}=51.3^{\circ} \mathrm{C}$ and $T_{\text {earth }}^{100}=43.5^{\circ} \mathrm{C} ; T_{\text {heaven }}^{200}=116.0^{\circ} \mathrm{C}, T_{\text {man }}^{200}=72.8^{\circ} \mathrm{C}$ and $T_{\text {earth }}^{200}=53.4^{\circ}$, respectively. The predicted temperature contours on the plane of acupoint GB38 and the temperature profile along the line connected by nodes $A$ and $B$ are shown in Fig. 9 and Fig. 10. The relation of the predicted temperature $(T)$ and the depth $(x)$ is expressed by the equations given below

$$
\begin{aligned}
& T=100-1.374 \times 10^{-1} x+1 \times 10^{-4} x^{2}-6 \times 10^{-8} x^{3}+2 \times 10^{-11} x^{4}-2 \times 10^{-15} x^{5}+1 \times 10^{-19} x^{6} \\
& T=200-3.48 \times 10^{-1} x+3 \times 10^{-4} x^{2}-2 \times 10^{-7} x^{3}+4 \times 10^{-11} x^{4}-6 \times 10^{-15} x^{5}+3 \times 10^{-19} x^{6}
\end{aligned}
$$

According to equations (3), (4) and (5) for the burning moxa cones with the temperatures at 60,100 and $200^{\circ} \mathrm{C}$, the temperatures at the "heaven" are decreased to $47.8,68.1$ and $116.0^{\circ} \mathrm{C}$, respectively. In the scarring type (moxa temperatures are 100 and $200^{\circ} \mathrm{C}$ ), the temperature decrease from the skin surface to the "heaven" is faster ( 31.9 and $84{ }^{\circ} \mathrm{C}$ in between the skin surface and the "heaven" position) than that of the non-scarring type $\left(12.2^{\circ} \mathrm{C}\right.$ in between the skin surface and the "heaven" position) since our human body has a larger thermal capacity than the moxa. The temperature, as a result, will quickly reach the human body's temperature $\left(37^{\circ} \mathrm{C}\right)$. In summary, the higher the moxa temperature, the more rapid temperature decrease will be.

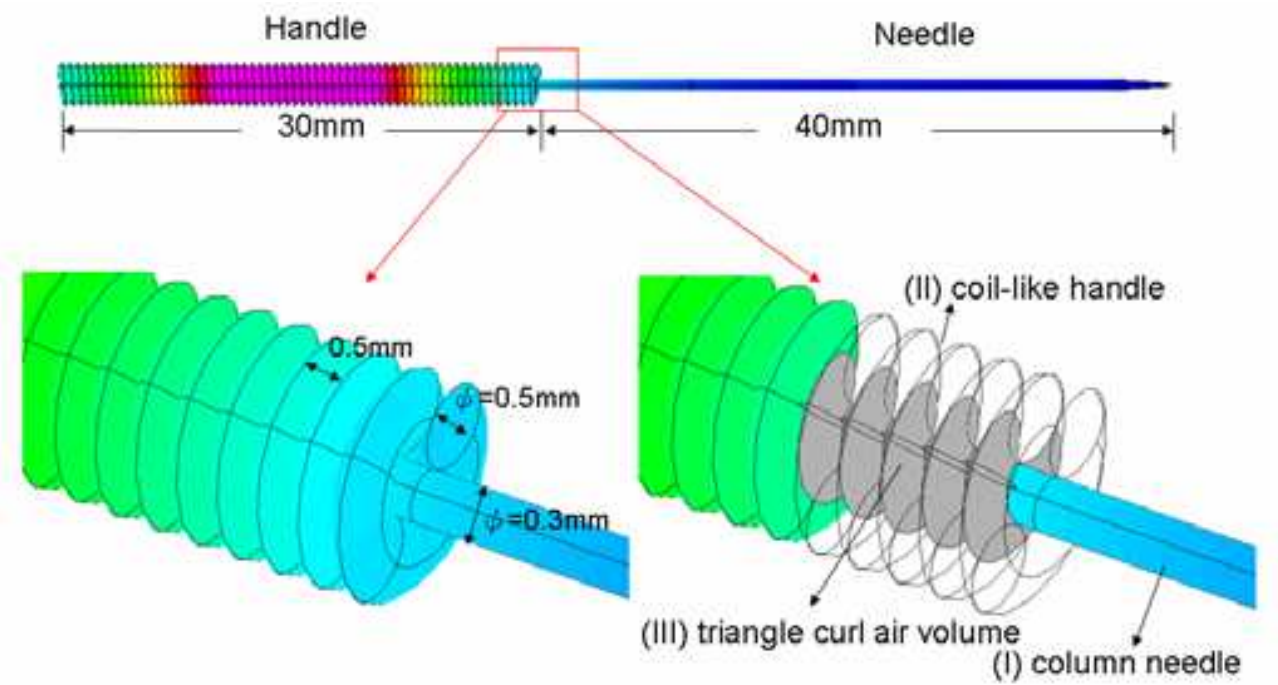

Fig. 11. Acupuncture needle is composed of one-column needle (portion I) and one coil-like handle (portion II), which covers the column needle

\section{(B) Warm needle moxibustion therapy}

In warm needle moxibustion, a needle assembly for the acupuncture includes a column needle (portion I) with its head having a sharp end and one coil-like handle (portion II), which covers the dull end of the column needle (Fig. 11). Between the column needle and 
the coiled handle, there is a triangle air volume (portion III). Figure 11 shows the investigated 1.5-inch acupuncture needle. A hybrid mesh system, containing both of the structured- and unstructured-type meshes shown in Fig. 12, is generated from a total number of 7,421 mesh points. The mesh density has been properly distributed so that the predicted solutions can accurately represent the physical phenomenon.

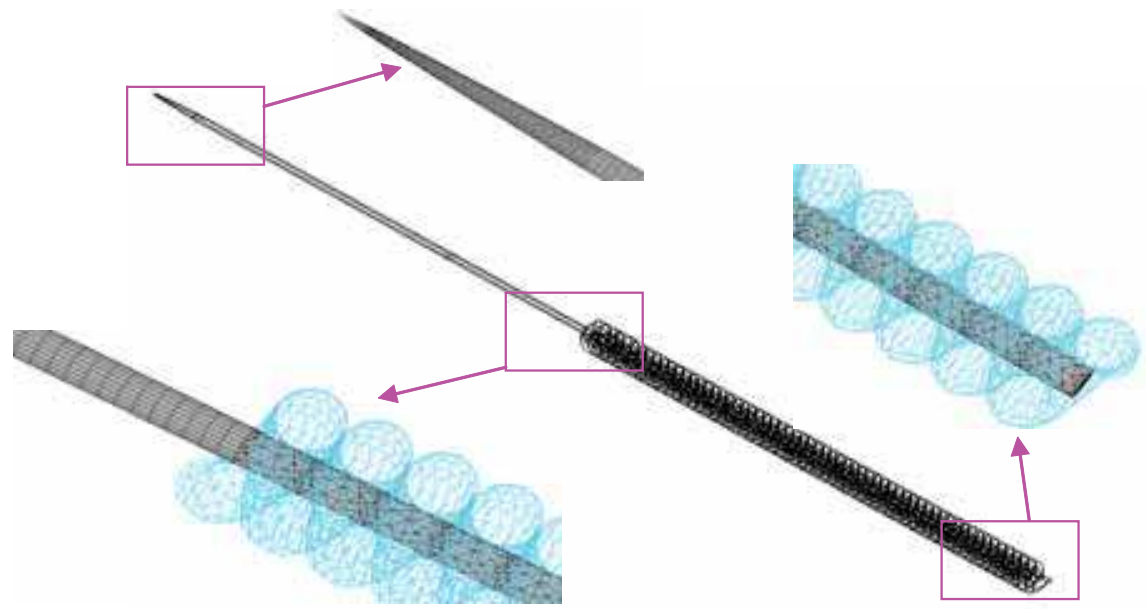

Fig. 12. The surface mesh points generated on the needle for acupuncture use

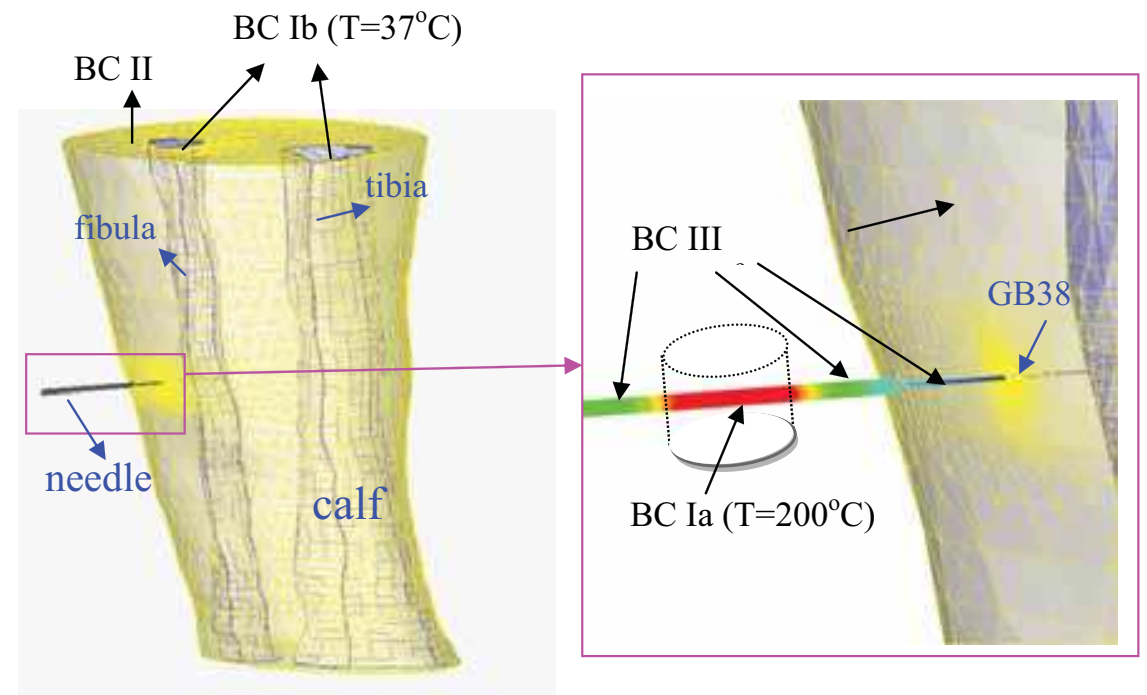

BC Ia: isothermal $\left(\mathrm{T}=200{ }^{\circ} \mathrm{C}\right) \quad \mathrm{BC}$ Ib: isothermal $\left(\mathrm{T}=37^{\circ} \mathrm{C}\right)$

BC II: symmetry $\quad$ BC III: external heat transfer (by convection)

Fig. 13. Schematic of the boundary condition types for the acupuncture needle inserted to the acupoint GB38 
The boundary conditions are applied on the calf section with the needle shown in Fig. 13, where BC I, II and III represent the isothermal, symmetric and convection types of boundary conditions, respectively. BC Ia shows the boundary of needle handle which has a moxa. The temperatures in the bone zone (BC Ib), including both fibula and tibia, are specified as $37^{\circ} \mathrm{C}$ to simulate the human body temperature. The symmetric conditions at the upper and bottom sides of the calf section (BC II), which connects knee and foot, are specified to account for the same structures of muscle tissues with knee and foot. BC III is normally chosen to simulate the transfer of heat to/ from the surrounding (i.e., the area outside of the computational system) by convection. This subtype is used to fix either the wall temperature or the heat flux. On the wall of $\mathrm{BC} \mathrm{II}$, it is prescribed by equation (2).

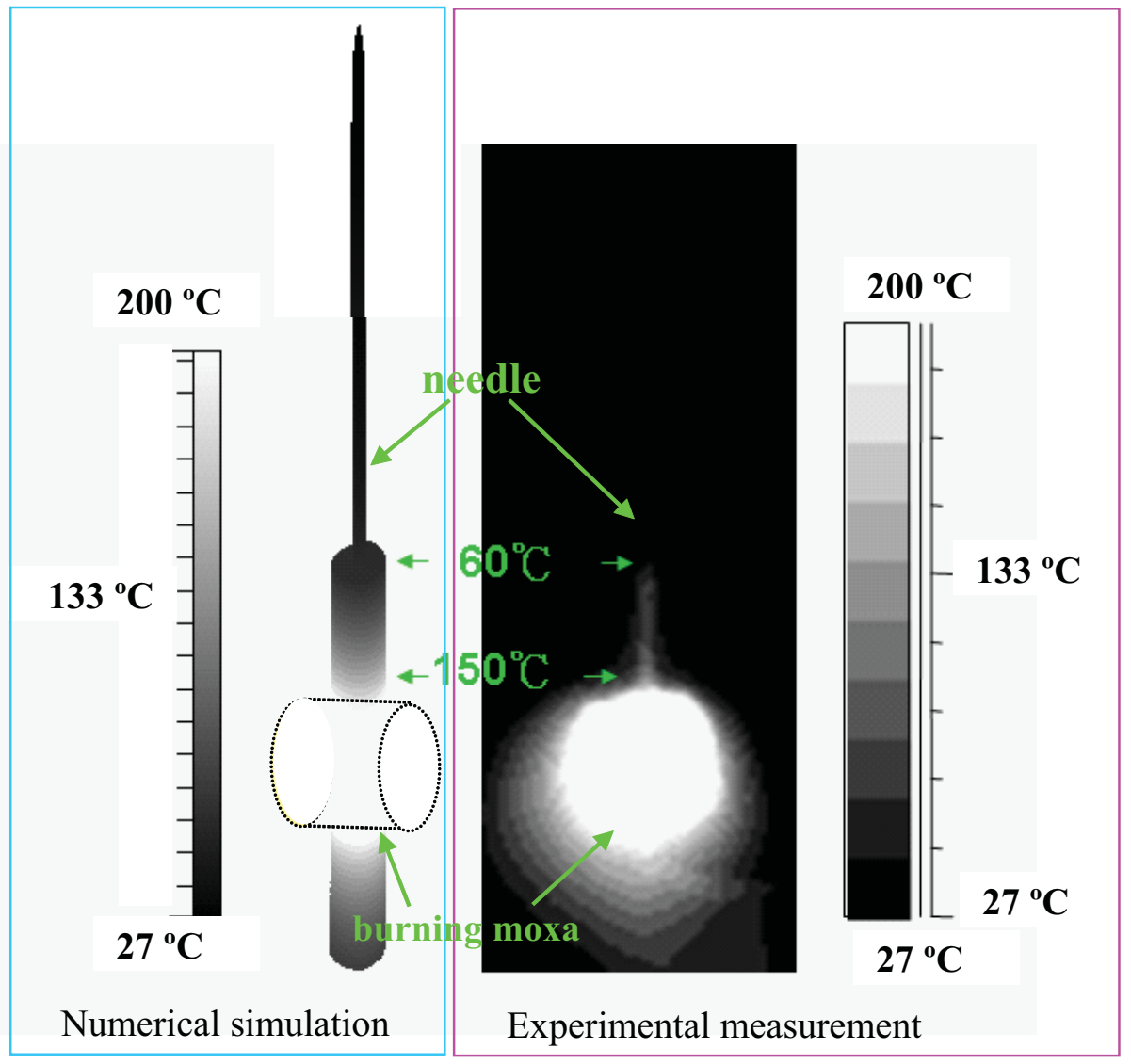

Fig. 14. Comparison of the numerically predicted and the experimentally measured temperatures for the burning moxa stick applied on the handle of the acupuncture needle. The temperature of burning moxa is $200^{\circ} \mathrm{C}$. Temperature gradient will be established across the needle, starting from the needle handle and ending at the needle head

In TCM, acupuncture needle can be made from stainless steel, iron, copper, silver and pottery etc. For the safety and cost effectiveness reasons, stainless steel is now more popular. 
This study employs the normal stainless steel needle $(1.5$ inch needle, $7 \mathrm{~cm}$ total length with $3 \mathrm{~cm}$ length in the needle handle part) in the experiment and numerical simulation. The thermal conductivity, specific heat, density and heat transfer coefficient of the stainless steel are denoted as $k_{s}, C p_{s}, \rho_{s}$ and $h_{s}$, respectively. At the normal state with the room temperature ( $22{ }^{\circ} \mathrm{C}$ in this study), these coefficients are prescribed with the values of $k_{s}=16 \mathrm{~W} / \mathrm{m}{ }^{\circ} \mathrm{C}$, $C p_{s}=460 \mathrm{~J} \mathrm{~kg}^{\circ} \mathrm{C}, \rho_{s}=7,800 \mathrm{~kg} / \mathrm{m}^{3}$ and $h_{s}=7.9 \mathrm{~W} / \mathrm{m}^{2}{ }^{\circ} \mathrm{C}$ (The Engineering Tool Box, http:/ / www.engineeringtoolbox.com/ ), respectively. The other associated coefficients are tabulated in Table 1. The predicted convergent temperature, which is plotted in Fig. 14, on the needle surface is seen to distribute similarly to the experimentally measured values by IR image.

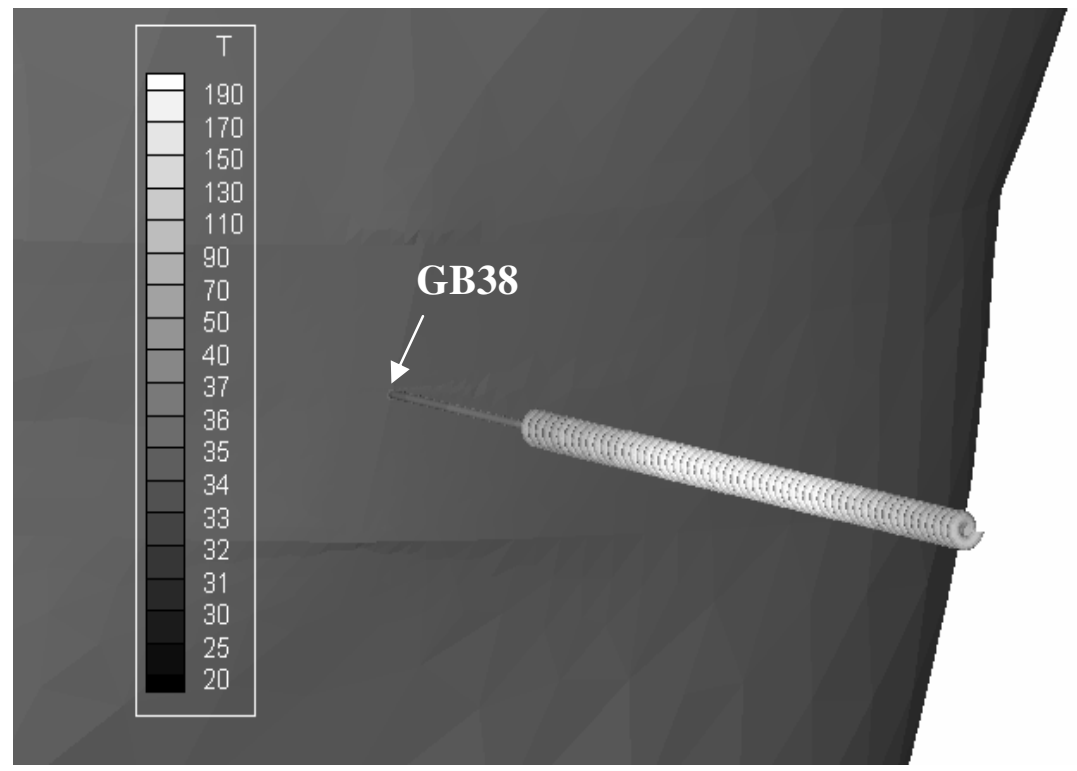

Fig. 15. The predicted skin surface temperature contours for the warm needle applied at the location near the acupoint GB38

Figure 15 shows the predicted temperature contours near the acupoint GB38 under the warm needle moxibution. Around the skin surface of GB38 (Fig. 16), the surface temperature near the needle is predicted to be about $36^{\circ} \mathrm{C}$, which is $1^{\circ} \mathrm{C}$ higher than those predicted at other skin surfaces $\left(\sim 35^{\circ} \mathrm{C}\right)$. Figure 17 shows the predicted temperature contours on the cutting plane passing through the acupuncture needle and GB38 acupoint. The tissue temperature around the needle is only $1^{\circ} \mathrm{C}$ higher than the others. Since the needle is smaller in comparison with the human body, the effect of the burning moxa on the needle handle is relatively less significant. In TCM, warm needle is involved in the acupuncture with burning moxa. From Figs. 16 and 17, we can understand why this treatment isn't called as the hot needle, even the burning moxa can reach the temperature that is as high as $200^{\circ} \mathrm{C}$. Figure 18 shows the predicted temperature profile along the center line of the acupuncture needle. From this profile, we can see that the temperature can be varied from $200{ }^{\circ} \mathrm{C}$ (burning moxa section) to $36{ }^{\circ} \mathrm{C}$ (skin surface) in a short length of $2 \mathrm{~cm}$. We can also observe 
that the temperatures at locations beneath of the skin surface of depths $0 \mathrm{~mm}, 1 \mathrm{~mm}, 2 \mathrm{~mm}$, $3 \mathrm{~mm}$ and $4 \mathrm{~mm}$ are $36.00^{\circ} \mathrm{C}, 35.63^{\circ} \mathrm{C}, 35.59^{\circ} \mathrm{C}, 35.62^{\circ} \mathrm{C}$ and $35.66^{\circ} \mathrm{C}$, respectively.

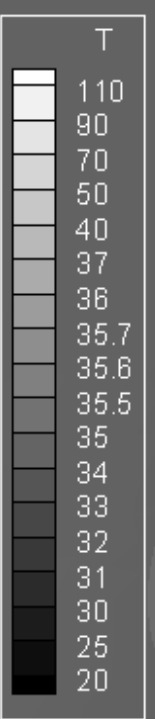

\section{GB38}

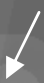

Fig. 16. The predicted skin surface temperature contours very near the acupoint GB38

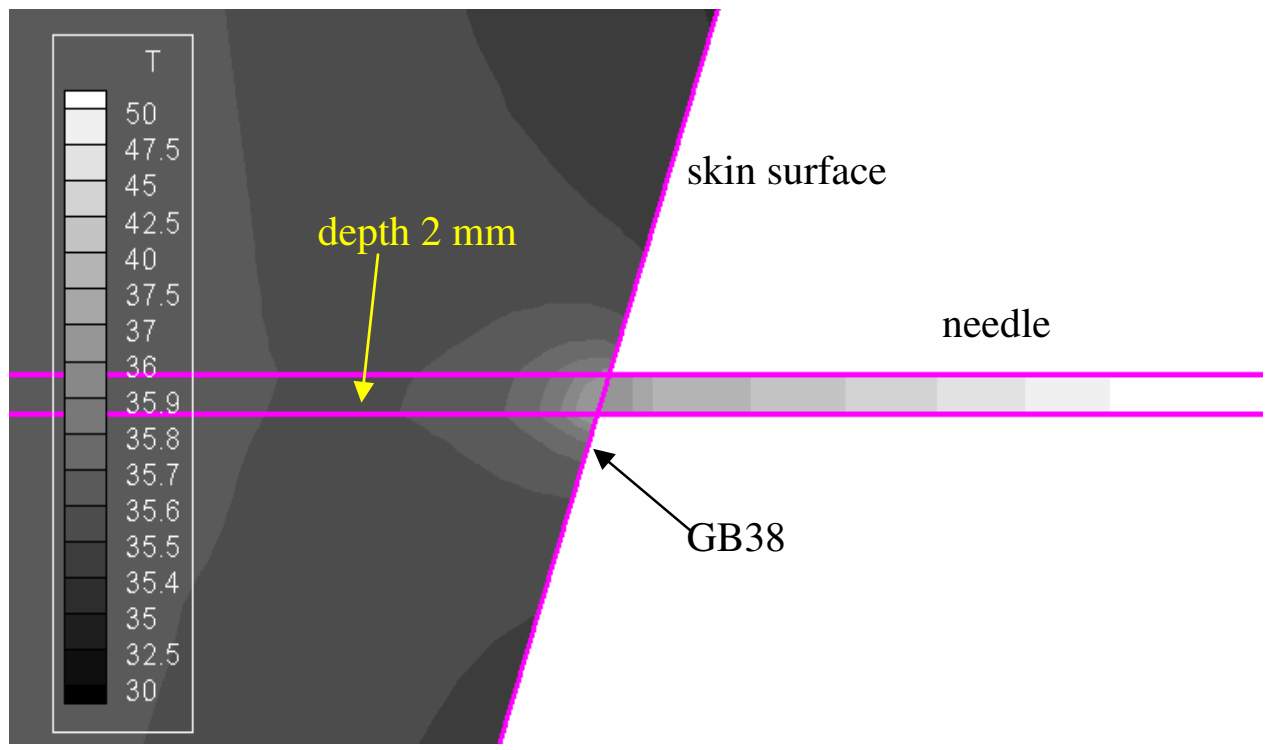

Fig. 17. The predicted temperature contours on the cutting plane, which passes through the acupoint GB38 


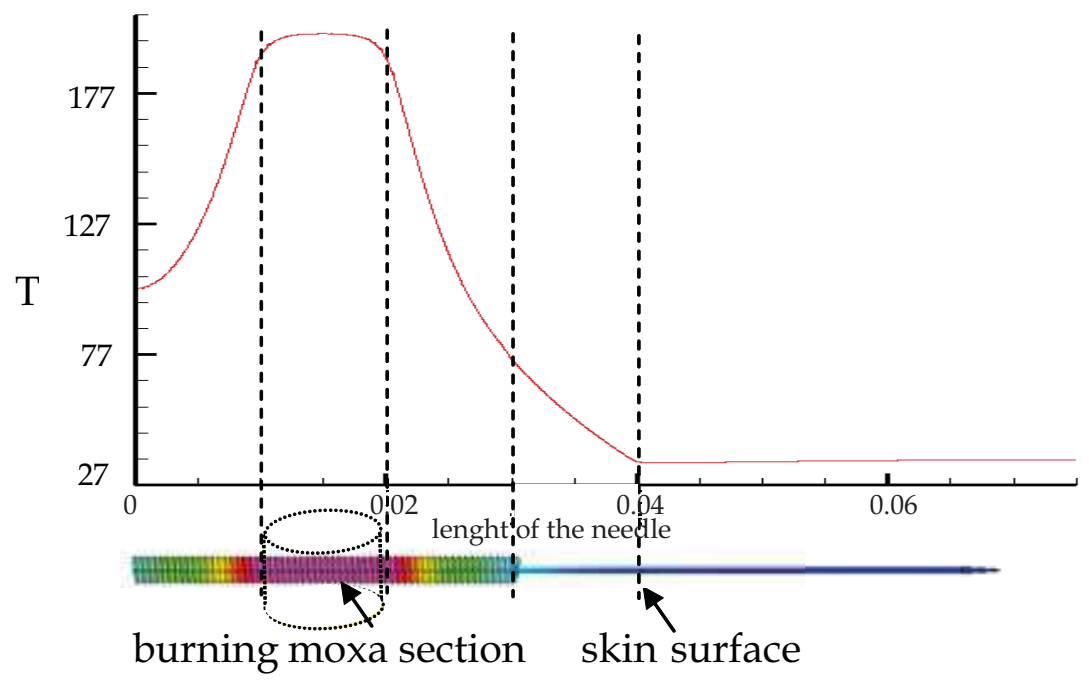

Fig. 18. The predicted temperature distribution along the centerline of the acupuncture needle for a warm needle applied at the acupoint GB38

\section{Conclusions}

In the present study, both of the experimental measurement and the numerical simulation have been conducted to get the temperature distribution near the acupoint which is subjected to a direct and a warm needle moxibustion treatments. The predicted temperature contours on the skin and needle surface are shown to agree well with the experimentally measured results. Moreover, the temperature contours of the tissues beneath of the skin surface have been also numerically predicted. In direct moxibustion, even for the lower temperature treatment type (non-scaring type, moxa temperature equal to $60{ }^{\circ} \mathrm{C}$ ), human tissue temperature is still increased by $12{ }^{\circ} \mathrm{C}$ at the heaven position. This explains why moxibustion rather than acupuncture has a better ability to treat severe diseases. In warm needle moxibustion, along the centerline of the acupuncture needle the temperature decreases very rapidly from the burning moxa section $\left(200{ }^{\circ} \mathrm{C}\right)$ to the skin surface $\left(36{ }^{\circ} \mathrm{C}\right)$. The temperature near the needle is only $1^{\circ} \mathrm{C}$ higher than those predicted at other places. This predicted phenomenon explains why we call it as the warm needle rather than as the hot needle treatment. These results are fundamentally important in the study of TCM. However, the physiological effect of warm needle moxibustion should include the contributions of acupuncture. For this reason, a better understanding of the total effect of the human body needs more intensive studies.

\section{Acknowledgments}

The financial support by the National Science Council under Grants NSC 97-2221-E-002-250MY3 is gratefully acknowledged. The authors also will acknowledge their thanks to Prof. Ping-Hei Chen who kindly provided us the FLIR system to perform temperature measurement. 


\section{References}

[1] Blake, A. S. T., Petley, G. W., and Deakin, C. D., Effects of changes in packed cell volume on the specific heat capacity of blood: implications for studies measuring heat exchange in extracorporeal circuits. British Journal of Anaesthesia, 84(1), 2000, pp. 28-32.

[2] CFD-ACE-GUI User Manual Volume II. CFD Research Corporation, 2003, pp. 85-94.

[3] Chang, K. W., Meridian Anatomy. Zhi-Yang Press, 1999, pp. 47.

[4] Cohen, M., Kwok, G., and Cosic, I., Acupuncture needles and the Seebeck effect: do temperature gradients produce electro-stimulation? Acupuncture and Electro therapeutics Research, 22, 1997, pp. 9-15.

[5] Construction of ThermaCAM SC500 Operator's Manual. FLIR Systems, 1999.

[6] Fei, L., Researches and developments of meridian physical basic and function experiments. Chinese Science Bulletin, 43(6), 2000, pp. 658-672.

[7] Huang, V. C., and Sheu, T. W. H., On a dynamical view on the meridian transmission. Journal of Accord Integrative Medicine, 4(2), 2008, pp.97-107.

[8] Huang, V.C., and Sheu, T. W. H., Tissue fluids in microchannel subjected to an externally applied electric potential. International Journal for Numerical Methods for Heat \& Fluid Flow, 19(1), 2009, pp. 64-77.

[9] Li, C., Jiang, Z., and Li, Y., Therapeutic effect of needle warming through moxibustion at twelve shu points on rheumatoid arthritis. Journal of Traditional Chinese Medicine, 19(1), 1999, pp. 22-26.

[10] Liu, G. J., Traditional Chinese Moxibustion. Nanchang, The Jiangxi Press of Science and Technology, 1999, pp. 339-352.

[11] Maoshing, N., (translator) The Yellow Emperor's Classic of Medicine: A New Translation of the Neijing Suwen with Commentary. Boston, 1995.

[12] Murat, T., Unal, C., and Cem, P., The bio-heat transfer equation and its applications in hyperthermia treatments. Engineering Computations, 23(4), 2006, pp. 451-463.

[13] Nishi, Y., and Gagge, A. P., Direct evaluation of convective heat transfer coefficient by naphthalene sublimation. Journal of Applied Physiology, 29(6), 1970, pp. 830-838.

[14] Sheu, T. W. H., and Huang, V. C., Development of an electro osmotic flow model to study the dynamic behavior in human meridian. International Journal for Numerical Methods in Fluids, 56, 2008, pp. 739-751.

[15] The engineering toolbox. Tools and Basic Information for Design, Engineering and Technical Applications, http:/ / www.engineeringtoolbox.com/ .

[16] Tsuei, J. J., The science of acupuncture - theory and practice. IEEE Engineering in Medicine and Biology Magazine, May/ June, 1996, pp. 52-57.

[17] Unschuld, P. U., Introductory Readings in Classical Chinese Medicine. Kluwer Academic Publishers, Dordrecht, Holland, 1988.

[18] Wiseman, N., and Feng, Y., A Practical Dictionary of Chinese Medicine. Paradigm Publications, Brookline, MA, 1998, pp. 664.

[19] Wu, M. X., Liu X. X., and Wu. B., The moxibustion influence of tendency in rehabilitation for mouse osteoporosis fracture. Moderate Rehabilitation, 5(6), 2001, pp. 46-47.

[20] Yang, J. K., Meridian Cross-section Anatomy. Shang Hai Science Technology Press, Chinese, 1997, pp. 76.

[21] Zhang, Q. W., Chinese Moxibustion Handbook. Tianjin, The Tianjin Press of Science and Technology, 1993, pp. 1-5.

[22] Zhu, B., Scientific Foundations of Acupuncture and Moxibustion. Qingdao Press, Qingdao, 1998. 


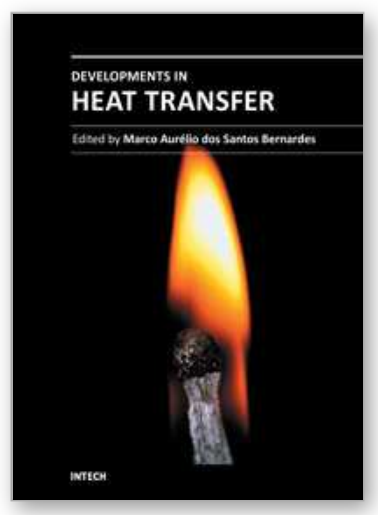

\author{
Developments in Heat Transfer \\ Edited by Dr. Marco Aurelio Dos Santos Bernardes
}

ISBN 978-953-307-569-3

Hard cover, 688 pages

Publisher InTech

Published online 15, September, 2011

Published in print edition September, 2011

This book comprises heat transfer fundamental concepts and modes (specifically conduction, convection and radiation), bioheat, entransy theory development, micro heat transfer, high temperature applications, turbulent shear flows, mass transfer, heat pipes, design optimization, medical therapies, fiber-optics, heat transfer in surfactant solutions, landmine detection, heat exchangers, radiant floor, packed bed thermal storage systems, inverse space marching method, heat transfer in short slot ducts, freezing an drying mechanisms, variable property effects in heat transfer, heat transfer in electronics and process industries, fission-track thermochronology, combustion, heat transfer in liquid metal flows, human comfort in underground mining, heat transfer on electrical discharge machining and mixing convection. The experimental and theoretical investigations, assessment and enhancement techniques illustrated here aspire to be useful for many researchers, scientists, engineers and graduate students.

\title{
How to reference
}

In order to correctly reference this scholarly work, feel free to copy and paste the following:

Chinlong Huang and Tony W. H. Sheu (2011). Study of the Heat Transfer Effect in Moxibustion Practice, Developments in Heat Transfer, Dr. Marco Aurelio Dos Santos Bernardes (Ed.), ISBN: 978-953-307-569-3, InTech, Available from: http://www.intechopen.com/books/developments-in-heat-transfer/study-of-the-heattransfer-effect-in-moxibustion-practice

\section{INTECH}

open science | open minds

\section{InTech Europe}

University Campus STeP Ri

Slavka Krautzeka 83/A

51000 Rijeka, Croatia

Phone: +385 (51) 770447

Fax: +385 (51) 686166

www.intechopen.com

\section{InTech China}

Unit 405, Office Block, Hotel Equatorial Shanghai

No.65, Yan An Road (West), Shanghai, 200040, China

中国上海市延安西路65号上海国际贵都大饭店办公楼 405 单元

Phone: +86-21-62489820

Fax: $+86-21-62489821$ 
(C) 2011 The Author(s). Licensee IntechOpen. This chapter is distributed under the terms of the Creative Commons Attribution-NonCommercialShareAlike-3.0 License, which permits use, distribution and reproduction for non-commercial purposes, provided the original is properly cited and derivative works building on this content are distributed under the same license. 